\title{
HUBUNGAN ANTARA PENGETAHUAN DAN SIKAP TENTANG PREMENSTRUAL SYNDROME DENGAN PERILAKU DALAM MENGATASI PREMENSTRUAL SYNDROME PADA MAHASISWA JURUSAN KEBIDANAN RANGKASBITUNG POLTEKKES KEMENKES BANTEN TAHUN 2015
}

\author{
*Nintinjri Husnida, *Hani Sutianingsih
}

\begin{abstract}
Abstrak
Premenstrual Syndrome meupakan suatu kondisi dimana wanita lebih sensitif terhadap perasaan dan kondisi tubuhnya dalam bentuk sekumpulan gejala fisik dan mental. Keluhan yang dialami bisa bervariasi dari bulan ke bulan bisa menjadi lebih ringan ataupun lebih berat. Sekitar $80 \%$ hingga 95\% wanita antara 16-45 tahun mengalami gejala-gejala Premenstrual Syndrome yang dapat mengganggu. Gejalanya berupa pusing, depresi serta perasaan sensitive berlebihan sekitar dua minggu sebelum haid biasanya dianggap hal yang wajar bagi wanita usia produktif sekitar $40 \%$ wanita berusia 14-50 tahun. Berdasarkan penelitian yang disponsori WHO didapatkan hasil bahwa gejala Premenstrual Syndrome dialami oleh $23 \%$ wanita Indonesia. Angka ini menunjukan bahwa penderita Premenstrual Syndrome di Indonesia cukup tinggi sehingga perlu dilakukan upaya untuk mencegah dan mengatasi gejala Premenstrual Syndrome dalam bentuk perilaku yang tepat.

Penelitian ini bertujuan untuk mengetahui hubungan antara pengetahuan dan sikap tentang Premenstrual Syndrome dengan perilaku mengatasi Premenstrual Syndrome pada mahasiswa Jurusan Kebidanan Rangkasbitung Poltkkes Kemenkes Banten tahun Jenis penelitian ini adalah kuantitatif dengan analitik observasional menggunakan pendekatan Cross Sectional. Jumlah sampel yang digunakan 150 responden., berdasarkan rumus pengambilan sampel menurut Slovin. Data penelitian diambil secara primer menggunakan kuesioner. Analisis data untuk mengetahui hubungan antar variabel menggunakan Chi-Square.

Hasil penelitian menunjukkan tidak ada hubungan yang signifikan antara pengetahuan dan sikap tentang Premenstrual Syndrome. Saran untuk Jurusan Kebidanan Rangkasbitung untuk dapat mengoptimalkan peran organisasi kemahasiswaan dibawah jurusn agar dapat memotivasi mahasiswa untuk memiliki perilaku yang baik tentang Premenstrual Syndrome dengan metode yang menarik dan efektif.
\end{abstract}

Kata kunci $\quad$ : Pengetahuan, Sikap, Perilaku, Premenstrual Syndrome *Poltekkes Kemenkes Banten 


\title{
RELATIONSHIP BETWEEN KNOWLEDGE AND ATTITUDE OF PREMENSTRUAL SYNDROME WITH BEHAVIOR IN OVERCOMING PREMENSTRUAL SYNDROMEAMONG THE STUDENT OF RANGKASBITUNG MIDWIFERY DEPARTMENT OF POLTEKKES KEMENKES BANTEN IN 2015
}

\author{
*Nintinjri Husnida, *Hani Sutianingsih
}

\begin{abstract}
Premenstrual Syndrome is a condition in which women are more sensitive to the feelings and the condition of the body in the form of a set of physical and mental symptoms. Complaints experienced can vary from month to month can be lighter or heavier. About $80 \%$ to $95 \%$ of women between 16-45 years of experience symptoms of Premenstrual Syndrome which can be annoying. Symptoms include dizziness, depression and feelings of excessive sensitivity about two weeks before menstruation is usually considered to be a natural thing for women of childbearing age about $40 \%$ of women aged 14-50 years. Based on WHO-sponsored study showed that the symptoms of Premenstrual Syndrome experienced by $23 \%$ of Indonesian women. This figure shows that Premenstrual Syndrome sufferers in Indonesia is quite high so it needs to be done to prevent and treat symptoms of Premenstrual Syndrome in the form of appropriate behavior.

This study aims to determine the relationship between knowledge and attitudes about Premenstrual Syndrome with the behavior of the students of Department of Obstetrics Rangkasbitung Poltekkes Banten in 2015. This research is a quantitative analytical observational study using cross sectional approach. The samples used 150 respondents., Based on sampling according to Slovin formula for taking samples of well known population. Primary research data taken using a questionnaire. Data analysis to determine the relationship between variables are calculated using Chi-Square.

The results showed no significant relationship between the kowledge and attitude of Premenstrual Syndrome with overcoming Premenstrual Syndrome. Advice to the Department of Midwifery of Rangkasbitung is to optimize the role of student organizations monitored by department of midwifery of Rangkasbitung in order to motivate the students to have a good knowledge and behavior of Premenstrual Syndrome with attractive and effective method.
\end{abstract}

Keywords : Knowledge, attitude, Behavior, Premenstrual Syndrome *Poltekkes Kemenkes Banten 


\section{Pendahuluan}

Menstruasi sebagai tanda berfungsinya organ reproduksi wanita, merupakan fase yang harus dipersiapkan dengan baik. Menstruasi terjadi karena sel telur yang tidak dibuahi oleh sperma sehingga menyebabkan meluruhnya selsel endometrium dalam rahim. Siklus menstruasi melibatkan beberapa tahap yang dikendalikan oleh interaksi hormone. Ketidakseimbangan hormone akibat interaksi ini kadang-kadang menimbulkan ketidaknyamanan pada wanita sebelum datang menstruasi yang dikenal dengan istilah Premenstrual Syndrome. (Kinanti, 2009)

Premenstrual Syndrome meupakan suatu kondisi dimana wanita lebih sensitif terhadap perasaan dan tubuhnya dalam bentuk sekumpulan gejala fisik dan mental. Ini merupakan kondisi medis umum terkait dengan siklus menstruasi yang sering berhubungan dengan naik turunnya kadar hormone progesteron dan estrogen yang terjadi selama siklus menstruasi. Keluhan yang dialami biasa bervariasi dari bulan ke bulan bisa menjadi lebih ringan ataupun lebih berat. (Andre s, 2009 \& Azra K, 2009)

Sekitar $80 \%$ hingga $95 \%$ wanita antara 16-45 tahun mengalami gejalagejala Premenstrual Syndrome yang dapat mengganggu. Gangguan kesehatan berupa pusing, depresi serta perasaan sensitif berlebihan sekitar dua minggu sebelum haid biasanya dianggap hal yang wajar bagi wanita usia produktif sekitar 40\% wanita berusia 14-50 tahun. (Yuliarti N, 2005)

Berdasarkan penelitian yang disponsori WHO didapatkan hasil bahwa gejala Premenstrual Syndrome dialami oleh $23 \%$ wanita Indonesia. Angka ini menunjukan bahwa penderita Premenstrual Syndrome di Indonesia cukup tinggi sehingga perlu dilakukan upaya untuk mencegah dan mengatasi gejala Premenstrual Syndrome dalam bentuk perilaku yang tepat. (Suparman, 2012)

Terdapat beberapa perilaku yang dapat dilaksanakan dalam mengatasi Premenstrual Syndrome diantaranya dengan meminta konseling kepada tenaga kesehatan, modifikasi gaya hidup dengan mengubah pola makan, olahraga teratur, melakukan komunikasi dengan orang terdekat dan dengan menggunakan obat-obatan apabila timbul gejala Premenstrual Syndrome yang berat . (Yuliarti N, 2009)

Jurusan Kebidanan Rangkasbitung Poltekkes Kemenkes Banten sebagai perguruan tinggi kesehatan bidang kebidanan yang seluruh peserta didiknya 
berjenis kelamin perempuan yang semuanya berada pada rentang usia reproduksi sangat rentan mengalami gejala Premenstrual Syndrome dalam setiap awal siklus haidnya. Sehingga Penulis merasa tertarik untuk mengetahui tentang "Hubungan antara Pengetahuan dan Sikap tentang Premenstrual Syndrome (PMS) dengan Perilaku dalam Mengatasi Premenstrual Syndrome (PMS) pada mahasiswa Jurusan Kebidanan Rangkasbitung Poltekkes Kemenkes Banten tahun $2015 "$

\section{Metodologi Penelitian}

Penelitian ini merupakan penelitian kuantitatif dengan pendekatan cross sectional yang menganalisis mengenai hubungan antara pengetahuan tentang Premenstrual Syndrome dan sikap mengenai Premenstrual Syndrome terhadap perilaku mengatasi Premenstrual Syndrome pada mahasiswa Jurusan Kebidanan Rangkasbitung Poltekkes Kemenkes Banten. Populasi penelitian ini adalah seluruh mahasiswa Jurusan Kebidanan Rangkasbitung Poltekkes Kemenkes Banten, sedangkan sampel yang digunakan untuk pengambilan data ini sejumlah 150 orang sesuai rumus Slovin untuk tingkat error $5 \%$. (Suharsaputra, 2012)

\section{Hasil Penelitian}

Distribusi karakteristik responden dapat dilihat pada tabel 1 berikut ini:

Tabel 1

Distribusi Frekuensi Pengetahuan Responden Tentang Premenstrual Syndrome

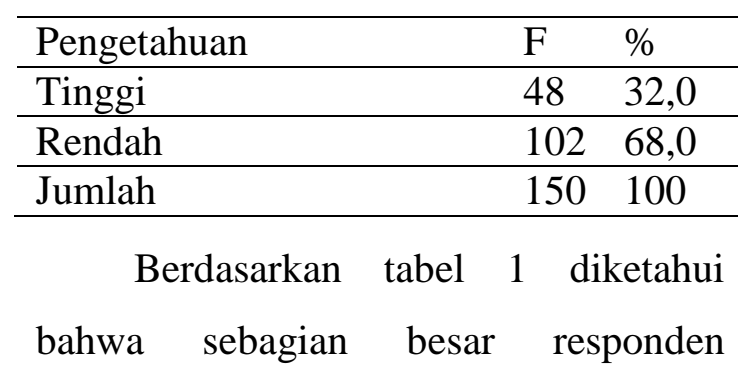
mempunyai pengetahuan tentang Premenstrual Syndrome dalam kategori rendah sebesar $68 \%$, sementara $32 \%$ dengan kategori pengetahuan yang tinggi tentang Premenstrual Syndrome.

Tabel 2

Distribusi Frekuensi Sikap Responden Terhadap Premenstrual Syndrome

\begin{tabular}{lcc}
\hline \multicolumn{1}{c}{ Sikap responden } & F & $\%$ \\
\hline Baik & 88 & 58.7 \\
Kurang Baik & 62 & 41.3 \\
\hline Jumlah & 150 & 100 \\
\hline
\end{tabular}

Berdasarkan tabel 2 diketahui bahwa sebesar $41.3 \%$ responden mempunyai sikap dengan kategori kurang baik.

Tabel 3

Distribusi Frekuensi Perilaku

Responden Dalam Mengatasi Premenstrual Syndrome

Perilaku mengatasi $\quad$ F $\%$
Premenstrual Syndrome

\begin{tabular}{lcc}
\hline Baik & 58 & 38.7 \\
\hline Kurang baik & 92 & 61.3 \\
\hline Jumlah & 150 & 100 \\
\hline
\end{tabular}


Berdasarkan tabel 3 diketahui bahwa sebesar $61.3 \%$ responden dalam kategori kurang baik yang berarti responden tidak selalu memiliki perilaku mengatasi Premenstrual Syndrome yang baik.

Tabel 4

Hubungan Antara Pengetahuan dengan

Perilaku mengatasi Premenstrual Syndrome

\begin{tabular}{ccccccc}
\hline \multirow{2}{*}{ Pengetahuan } & \multicolumn{3}{c}{ Perilaku mengatasi } & \multirow{2}{*}{ Total } \\
\cline { 2 - 5 } & \multicolumn{3}{c}{ Kremenstrual Syndrome } & & \\
\cline { 2 - 5 } & $\mathrm{N}$ & $\%$ & $\mathrm{~N}$ & $\%$ & $\mathrm{~N}$ & $\%$ \\
\hline Rendah & 61 & 59.8 & 41 & 40.2 & 102 & 100 \\
Tinggi & 31 & 64.6 & 17 & 35.4 & 48 & 100 \\
\hline Total & 92 & 61.3 & 58 & 38.7 & 150 & 100 \\
\hline \multicolumn{6}{c}{$p=0.703$} \\
\hline
\end{tabular}

Berdasarkan tabel 4 diketahui bahwa perilaku kurang baik dalam mengatasi Premenstrual Syndrome lebih banyak $(64,6 \%)$ terjadi pada responden yang memiliki pengetahuan tinggi, bila dibandingkan dengan responden yang memiliki pengetahuan rendah, hanya 59,8\% yang memiliki perilaku kurang baik dalam mengatasi Premenstrual Syndrome

Nilai $p$ pada analisis bivariat dengan uji chi square adalah 0.703 dapat diartikan bahwa tidak ada hubungan yang signifikan antara pengetahuan tentang Premenstrual Syndrome dengan perilaku mengatasi Premenstrual Syndrome.
Tabel 5

Hubungan Antara Sikap dengan Perilaku mengatasi Premenstrual Syndrome

\begin{tabular}{lcccccc}
\hline \multirow{3}{*}{ Sikap } & \multicolumn{3}{c}{$\begin{array}{c}\text { Perilaku mengatasi } \\
\text { Premenstrual } \\
\text { Syndrome }\end{array}$} & \multirow{2}{*}{ Total } \\
\cline { 2 - 5 } & $\begin{array}{c}\text { Kurang } \\
\text { baik }\end{array}$ & \multicolumn{2}{c}{ Baik } & & \\
\cline { 2 - 6 } & $\mathrm{N}$ & $\%$ & $\mathrm{~N}$ & $\%$ & $\mathrm{~N}$ & $\%$ \\
\hline Kurang Baik & 44 & 71 & 18 & 29 & 62 & 100 \\
Baik & 48 & 54.5 & 40 & 45.5 & 88 & 100 \\
\hline Total & 92 & 61.3 & 58 & 38.7 & 150 & 100 \\
\hline \multicolumn{5}{c}{$\boldsymbol{p = 0 . 0 6 2}$} \\
\hline
\end{tabular}

Berdasarkan tabel 5 diketahui bahwa perilaku kurang baik dalam mengatasi Premenstrual Syndrome lebih banyak terdapat $(71,0 \%)$ pada responden yang memiliki sikap kurang baik terhadap Premenstrual Syndrome, bila dibandingkan dengan responden yang memiliki sikap baik pada Premenstrual Syndrome, hanya $54,5 \%$ yang berperilaku kurang baik dalam mengatasi Premenstrual Syndrome.

Berdasarkan nilai $p$ pada analisis bivariat dengan uji chi square adalah 0.062 dapat diartikan bahwa tidak terdapat hubungan yang signifikan antara sikap dengan perilaku mengatasi Premenstrual Syndrome.

\section{Pembahasan}

\section{Pengetahuan tentang Premenstrual}

\section{Syndrome.}

Pada penelitian ini didapatkan hasil bahwa pada variabel pengetahuan 
tentang Premenstrual Syndrome sebagian besar responden berada pada tingkat pengetahuan rendah sebesar $68 \%$. Hal ini dapat dimungkinkan karena pengalaman responden mengenai penanganan Premenstual Syndrome masih kurang, terkait lama responden mengalami fase menstruasi dilihat dari menarche. Semakin lama responden mengalami menstruasi, maka akan semakin tinggi keinginan responden untuk mencari tahu cara menangani keluhan terkait menstruasi (Premenstrual Syndrome), sesuai pendapat Notoatmodjo bahwa "Pengetahuan pada dasarnya merupakan hasil dari penginderaan, sehingga seseorang dapat mengetahui suatu fenomena." Penginderaan didapat dari pengalaman. (Notoatmodjo, 2007)

Meskipun responden yang menjadi partisipan dalam penelitian ini semuanya adalah mahasiswa jurusan kebidanan yang cenderung telah terpapar informasi mengenai kesehatan reproduksi wanita terkait materi Premenstrual Syndrome, perlu ditelaah pula posisi semester berjalan yang sedang dijalani responden, karena materi mengenai kesehatan reproduksi berada pada semester II, sementara tidak semua responden berada pada posisi semester yang telah melewati semester II.
2. Sikap tentang Premenstrual Syndrome

Berdasarkan tabel 2 mengenai sikap responden tentang Premenstrual Syndrome sebagian besar responden berada pada kategori baik. Meskipun Sikap belum merupakan suatu tindakan atau aktifitas, akan tetapi merupakan sebuah faktor predisposisi suatu perilaku. Sikap secara nyata menunjukan adanya kesesuaian reaksi terhadap stimulus tertentu yang dalam kehidupan sehari-hari merupakan reaksi emosional terhadap stimulus sosial. Sikap merupakan hal yang penting dalam kehidupan sehari-hari, bila sikap itu sudah terbentuk dalam diri seseorang selanjutnya akan ikut menentukan tingkah lakunya terhadap sesuatu. ( Green , 2000)

Sikap yang utuh dipengaruhi oleh pengetahuan, keyakinan dan emosi seseorang. Seseorang yang telah terpapar informasi mengenai Premenstrual Syndrome akan membawa orang tersebut untuk berpikir kearah perilaku mengatasi Premenstrual Syndrome dengan baik. Bila dilihat dari tabel 2 responden lebih banyak yang mempunyai sikap positif atau baik terhadap penanganan Premenstrual Syndrome sebanyak $58.7 \%$. 


\section{Perilaku mengatasi Premenstrual} Syndrome.

Untuk variabel perilaku responden dalam mengatasi Premenstrual Syndrome didapatkan hasil sebagian besar responden memiliki perilaku yang kurang baik sebanyak 61.3\%. Apabila ditelaah menurut teori perilaku seharusnya terbentuk dari tiga komponen utama, yaitu komponen kognitif (pengetahuan), sikap (afektif) dan keterampilan (psikomotor). Dalam konteks ini setiap perbuatan seseorang dalam merespon sesuatu pastilah terkonseptualisasi dari ketiga ranah ini. Perbuatan seseorang atau respon seseorang didasari oleh seberapa jauh pengetahuannya terhadap rangsang tersebut. (Suparman E, 2011)

Bila dilihat dari teori ini, maka untuk membentuk perilaku responden yang baik dalam mengatasi Premenstrual Syndrome diperlukan sebuah pengetahuan yang adekuat tentang Premenstrual Syndrome itu sendiri, sementara bila dilihat dari tingkat pengetahuan responden mengenai Premenstrual Syndrome masih banyak yang memiliki pengetahuan yang rendah mengenai Premenstrual Syndrome, sehingga perilaku responden dalam mengatasi Premenstrual
Syndrome pun banyak dalam kategori kurang baik.

4. Hubungan Pengetahuan tentang Premenstrual Syndrome dengan perilaku mengatasi Premenstrual Syndrome

Secara teori, Notoatmodjo (2007) menjelaskan bahwa pengetahuan merupakan domain yang sangat penting dalam membentuk tindakan seseorang. Hasil ini tidak sejalan dengan teori tersebut yang refleksikan dalam bahwa perilaku yang didasari oleh pengetahuan akan lebih langgeng daripada perilaku yang tidak didasari oleh pengetahuan, karena perilaku merupakan tindakan atau perbuatan yang berawal dari pengamatan dan pembelajaran.

Pada penelitian ini tidak ditemukan adanya hubungan antara pengetahuan tentang Premenstrual Syndrome dengan perilaku mengatasi Premenstrual Syndrome. Seperti dikemukakan oleh Mubarak (2011) bahwa "Perilaku merupakan seperangkat perbuatan/ tindakan seseorang dalam melakukan respon terhadap sesuatu dan kemudian dijadikan kebiasaan karena adanya nilai yang diyakini. Perilaku manusia pada dasarnya terdiri atas komponen pengetahuan (kognitif), sikap (afektif), dan keterampilan (psikomotor). Dalam konteks ini, setiap perbuatan seseorang 
dalam merespon sesuatu pastilah terkonseptualisasi dari ketiga ranah ini. Perbuatan seseorang atau respon seseorang didasari oleh seberapa jauh pengetahuannya terhadap rangsang tersebut, bagaimana perasaan dan penerimaannya, dan seberapa besar keterampilannya dalam melaksanakan atau melakukan perbuatan yang diharapkan (Mubarak, 2011). Dalam konteks penelitian ini, sebagian besar responden berada pada kategori pengetahuan rendah tentang Premenstrual syndrome., sehingga tidak akan terbentuk satu perilaku atau tindakan yang tepat dalam mengatasi Premenstrual syndrome, karena tidak ada hal yang diyakini oleh responden mengenai urgensi Premenstrual syndrome serta cara mengatasinya. Seperti pada penelitian Qomarullah (2014) bahwa perilaku mengatasi Premenstrual syndrome seperti olah raga, dan latihan relaksasi (renang, yoga) penting untuk tubuh, agar dapat merelaksasi tubuh, pada penelitian ini, responden sebagian besar tidak melakukan teknik relaksasi sehingga penanganan Premenstrual syndrome menjadi terabaikan.

Menurut Suparman (2011) dan Andrews (2009) Penatalaksanaan non farmakoterapi, farmakoterapi dan operatif merupakan penanganan yang dapat dilakukan untuk mengatasi Premenstrual Syndrome sesuai dengan intensitas nyeri dan kondisi pasien. Penatalaksaan non farmakoterapi meliputi pengaturan makan, latihan dan relaksasi,modifikasi pola tidur dengan nyenyak. Secara farmakoterapi dengan menggunakan obat-obatan atau asupan vitamin seperti vitamin B6, diuretik, anti cemas, anti depresan, dan hormonal. Sedangkan penatalaksanaan operatif dilakukan hanya untuk kasus-kasus berat. Seperti pada penelitian Qomarullah (2014). berbagai jenis penanganan Premenstrual Syndrome tersebut kurang difahami oleh responden, hal ini bisa saja terjadi karena responden tidak mengalami gejala Premenstrual Syndrome yang berlebihan.

Tidak adanya hubungan antara pengetahuan dengan perilku dalam mengatasi Premenstrual Syndrome dapat disebabkan pengetahuan dengan kategori baik yang dimiliki responden tidak diterapkan kepada perilaku yang seharusnya dalam mengatasi Premenstrual Syndrome.

Karena hasil penelitian menunjukkan pengetahuan tidak signifikan berhubungan dengan perilaku dalam mengatasi Premenstrual 
Syndrome, maka diperlukan sebuah wahana yang tepat untuk menginformasikan penanganan yang tepat mengenai Premenstrual Syndrome, sehingga responden dapat lebih memahami dan mengaplikasikan perilaku yang tepat mengenai Premenstrual Syndrome.

\section{Hubungan Sikap tentang Premenstrual Syndrome dengan perilaku mengatasi Premenstrual Syndrome.}

Sikap merupakan hal yang penting dalam kehidupan sehari-hari, bila sikap sudah terbentuk dalam diri seseorang selanjutnya orang tersebut akan ikut menentukan perilakunya terhadap sesuatu. Dalam penelitian ini responden telah melalui berbagai fase tingkatan sikap mulai dari menerima, merespon, menghargai stimulus (mengenai Premenstrual Syndrome) dan bertanggung jawab atas pilihan pemikiran/pendapatnya terkait Premenstrual Syndrome. (Green, 2000).

Hasil analisa dari hubungan antara sikap tentang Premenstrual Syndrome dengan perilaku dalam mengatasi Premenstrual Syndrome tidak ditemukan adanya hubungan antara kedua variabel tersebut. Hal ini dapat dimungkinkan karena perilaku manusia secara operasional dibentuk oleh tiga faktor yang berhubungan satu sama lain yaitu faktor predisposisi, faktor pendukung dan faktor pendorong, sementara sikap merupakan salah satu komponen yang ada pada faktor predisposisi yang turut serta membentuk perilaku individu. Namun, sikap hanya merupakan suatu kecenderungan untuk mengadakan tindakan terhadap suatu obyek dengan cara menunjukan rasa suka atau tidak suka terhadap obyek tersebut, sehingga meskipun banyak responden yang memiliki sikap positif mengenai Premenstrual Syndrome, perilaku mengatasi Premenstrual Syndrome yang baik tidak terbentuk, karena masih banyak faktor lain yang mempengaruhi terbentuknya perilaku. Sehingga diperlukan adanya optimalisasi faktorfaktor yang berkontribusi terhadap perilaku tersebut.

( Green L, 2000 \& Suparman E, 2011)

Tidak ada hubungan antara sikap dengan perilaku mengatasi Premenstrual Syndrome pada hasil penelitian ini dimungkinkan karena adanya faktor lain yang merupakan faktor predisposisi dari bagian sikap yang belum tergali lebih dalam seperti kepercayaan, keyakinan, nilai-nilai, dan sebagainya. Selain itu hal ini juga bisa dimungkinkan sikap yang ditunjukkan mahasiswi menunjukkan 
perilaku tertutup sehingga terjadi bila respon terhadap stimulus tersebut masih belum dapat diamati orang lain (dari luar) secara jelas. Respon seseorang masih terbatas dalam bentuk perhatian, perasaan, persepsi, pengetahuan dan sikap terhadap stimulus yang bersangkutan menyebabkan sulitnya mengungkapkan suatu fakta.

Karena hasil penelitian menunjukkan pengetahuan dan sikap tidak signifikan berhubungan dengan perilaku dalam mengatasi Premenstrual Syndrome, maka diperlukan suatu komunikasi dan motivasi lebih dalam penggalian informasi agar lebih terbuka untuk mengungkap suatu variabel yang ingin diteliti. Selain itu responden dalam penelitian ini semuanya merupakan mahasiswa Jurusan Kebidanan, sehingga materi mengenai Premenstrual Syndrome pasti didapatkan dari pendidikan formal, sehingga untuk memperkuat terbentuknya perilaku yang positif mengenai Premenstrual Syndrome diperlukan sebuah wahana yang dapat memfasilitasi responden untuk dapat mempelajari mengenai materi Premenstrual Syndrome diluar pendidikan formal (dalam bentuk ekstra kulikuler yang berada dibawah jurusan), karena Jurusan Kebidanan Rangkasbitung telah mempunyai organisasi mahasiswa yang "concern" pada kesehatan reproduksi remaja, yaitu Pusat Informasi dan KonselingMahasiswa (PIK-M) maka keberadaan PIK-M ini dapat dimanfaatkan sebagai wahana penyampaian materi Premenstrual Syndrome dengan cara yang lebih bervariasi dan menarik dengan metode yang tidak kaku seperti dikelas. Materi Premenstrual Syndrome dapat diintegrasikan kedalam program kerja PIK-M dengan monitoring dari bidang kemahasiswaan sehingga akan lebih efektif diterima oleh responden yang dalam konteks penelitian ini adalah mahasiswa Jurusan Kebidanan Rangkasbitung.

\section{Simpulan}

1. Tingkat pengetahuan responden mengenai Premenstrual Syndrome sebagian besar berada pada kategori rendah yaitu sebanyak 68\%. Untuk sikap responden mengenai Premenstrual Syndrome sebagian besar berada pada kategori baik sebesar 58,7\%. Sementara untuk perilaku mengatasi Premenstrual Syndrome sebagian besar responden berada pada kategori kurang baik yaitu sebanyak $61.3 \%$,

2. Tidak terdapat hubungan yang signifikan antara pengetahuan tentang 
Premenstrual Syndrome dengan perilaku mengatasi Premenstrual Syndrome.

3. Tidak terdapat hubungan yang signifikan antara sikap mengenai Premenstrual Syndrome dengan perilaku mengatasi Premenstrual Syndrome.

\section{Daftar Pustaka}

Andrews G (2009). Buku ajar kesehatan reproduksi wanita. Jakarta: EGC.

Azra K (2009). Buku pintar cewek. Jakarta: Lafal Indonesia..

Green L (2000). Health promotion, planning, education and environmental approach. Mayfield Publishing Company

Kinanti S (2009). Rahasis pintar wanita. Yogyakarta: Aulia Publishing.

Mubarok WI (2011). Promosi kesehatan untuk kebidanan. Jakarta: Salemba Medika.

Notoatmodjo S (2010). Ilmu perilaku kesehatan. Jakarta : Rineka Cipta.

Notoatmodjo S (2007). Promosi kesehatan dan ilmu perilaku kesehatan. Jakarta : Rineka Cipta

Qomarullah S (2014). Hubungan tingkat pengetahuan Premenstrual Syndrome dengan perilaku mengatasi Premenstrual Syndrome pada mahasiswi STIKES PKU Muhammadiyah Surakarta. Surakarta.
Suharsaputra U (2012). Metodologi penelitian kuantitatif, kualitatif dan tindakan. Jakrta: Refika Aditama.

Suparman E (2011). Premenstrual Syndrome. Jakarta: EGC.

Yuliarti N(2009). A-Z woman healthy and beauty. Yogyakarta: Andi Offset. 